\section{Registration of a Drought-Resistant Chickpea Germplasm}

ICC 4958 IS A DESI CHICKPEA (Cicer arietinum L.) germplasm line collected from Madhya Pradesh, India (1) It has been identified as drought resistant (Reg. no. GP-113, PI 439824) by the scientific staff of the Legumes Program, International Crops Research Institute for the Semi-Arid Tropics (ICRISAT). It was subsequently identified for release by the ICRISAT Plant Material Identification Committee (PMIC) in 1992.

ICC 4958 was one of more than 1500 diverse germplasm lines screened for drought resistance under field conditions between 1978 and 1983 at ICRISAT Center and was one of the most drought-resistant entries evaluated (2). In spring plantings in western Asia, ICC 4958 also proved to be the most drought-resistant entry in trials conducted in the terminal drought environments at the International Center for Agricultural Research in the Dry Areas (ICARDA), Aleppo, Syria (3). Drought resistance of ICC 4958 was also validated in recent multilocational trials in India (4). Mean yield of ICC 4958 and Annigeri was 0.6 and $0.4 \mathrm{t} \mathrm{ha}^{-1}$, respectively. The yield of ICC 4958 was $120 \%$ of that of the mean yield of all entries in the stress environments $\left(0.5 \mathrm{tha}^{-1}\right)(5)$; in $1 \mathrm{yr}, \mathrm{ICC}$ 4958 yield relative to Annigeri reached as high as $157 \%$. When the mean yield of stress environments was $0.8 \mathrm{~g} \mathrm{ha}^{-1}$, the yield advantage of ICC 4958 ranged from 102 to $117 \%$.

Characteristic features of ICC 4958, as observed in the warmwinter, short-duration, terminal-drought environment represented by ICRISAT Center in peninsular India (6), are described below.

ICC 4958 is a brown-seeded desi type of chickpea. As in other desi types, it has the characteristic presence of the anthocyanin pigmentation in the foliage and stems. All comparisons of this drought-resistant germplasm are made with Annigeri, the best adapted variety for the peninsular Indian region. ICC 4958 is adapted to short duration, progressively increasing, terminal drought environments, such as at ICRISAT Center. It is semi-spreading and has a terminal branching growth habit. Branches are few $(15 \pm 1.8$ in ICC 4958; $22 \pm 4.3$ in Annigeri) but the canopy height is similar to that of Annigeri $(37 \pm 8.0 \mathrm{~cm})$. The compound leaves have 13 to 14 pinnules, as in Annigeri, but the areas of individual leaves of ICC 4958 are 77 and $113 \%$ larger in nonirrigated and irrigated treatments, respectively, because of larger pinnule size. Although the leaf size is large, the fewer nodes in ICC 4958 (149 \pm 26 , compared to $196 \pm 42$ in Annigeri) negatively compensate for the larger leaf size and, as a result, leaf area index is similar for the two genotypes.

The root system of ICC 4958, measured as root length and volume at flowering and pod-set-initiation stage, is $30 \%$ greater than that in Annigeri. Nodule mass, nodule activity (determined by acetylene reduction method), and the nitrate reductase activity are similar for ICC 4958 and Annigeri.

Flowering in ICC 4958 begins around $39 \mathrm{~d}$ after sowing, compared with $43 \mathrm{~d}$ in Annigeri. Differences in maturity are small, both with and without irrigation. They mature in about 88 and $103 \mathrm{~d}$ after planting under nonirrigated and irrigated conditions, respectively. Flowers are large and have the pinkish-purple color characteristic of desi types. The seed size is large for a desi types with a mean 100-seed mass of $30 \pm 0.3$ g compared to $19 \pm 1.2$ in Annigeri. Within a sample, seed weight may range from 10 to $46 \mathrm{~g} / 100$ seeds. Generally, there is only one seed pod $^{-1}$. The pod size is large and the pod bearing is less. This genotype is affected by the late wilt disease, caused by Fusarium oxysporum Schlecht.:Fr. f.sp. ciceri Timmer et al. (Haware, M.P., ICRISAT, personal communication). It is relatively less susceptible to pod borer (Helicov- erpa armigera [Hübner]) damage. In one comparison, the percent of borer-damaged pods in ICC 4958 was 22.2 , compared with 40.3 in Annigeri (Lateef, S.S., ICRISAT, 1991, personal communication).

This germplasm line can be introduced to give an advantage for relatively higher and stable yields in terminal drought-prone environments of 90 to $95 \mathrm{~d}$ duration, with a mean rainfed yield of $0.5-0.7 \mathrm{tha}^{-1}$. For environments of longer duration, ICC 4958 can be used as a donor parent to introgress the desirable trait of a larger root system into an adapted background. Seed of this germplasm accession is maintained by and can be obtained for research purposes through the Genetic Resources Program, ICRISAT, Patancheru, India.

N.P. SaXena, ${ }^{*}$ L. Krishnamurthy, and C. Johansen $(7)$

\section{References and Notes}

1. Pundir, R.P.S., K.N. Reddy, and Melak H. Mengesha. 1988. ICRISAT chickpea germplasm catalogue: passport information. Patanchen, A.P., 502324 , India.

2. International Crops Research Institute for the Semi-Arid Tropics. 1992. ICC 4958 a drought resistant chickpea. Plant Material Description no. 33. Patancheru, A.P. 502 324, India.

3. International Center for Agricultural Research in the Dry Areas. 1989. p. 185-191 In Food legume improvement program, Annual Report for 1988. Aleppo, Syria.

4. Eberhart, S.A., and W.A. Russell. 1966. Stability parameters for comparing varieties. Crop Sci. 6:36-40.

5. Saxena, N.P. 1987. Screening for adaptation to drought: case studies with chickpea and pigeonpea. p. 63-76. In Adaptation of chickpea and pigeonpea to abiotic stresses: Proc. Consultant's Workshop, 19 to 21 Dec 1984. ICRISAT, Patancheru, A.P., 502 324, India.

6. Saxena, N.P. 1984. Chickpea. P. 419-452 In P.R. Goldsworthy and N.M. Fisher (ed.). Physiology of tropical field crops. Wiley, New York.

7. N.P. Saxena, L.Krishnamurthy, and C. Johansen, Crop Physiology Unit, Legumes Program, ICRISAT, Patancheru, A.P. 502 324, India. ICRISAT Journal Article 1354. Accepted 30 April 1993. *Corresponding author.

Published in Crop Sci. 33:1424 (1993).

\section{Registration of AG-S4 Autogamous Broad-Leaf Birdsfoot Trefoil Germplasm}

AG-S4 (Reg. no. GP-7, PI566818) autogamous broad-leaf birdsfoot trefoil (Lotus corniculatus L.) germplasm was developed and released 10 December 1992 by the United States Department of Agriculture, Agricultural Research Service, in cooperation with the Oregon, Idaho, and Washington Agricultural Experiment Stations.

AG-S4 originated from a single autogamous clone identified in the broad-based MU-81 germplasm, a genetically diverse, self-incompatible population that was produced by three cycles of intercrossing plants from 56 foreign introductions and 35 experimental synthetics or cultivars $(1) . S_{2}$ seeds resulting from both unassisted selfing and hand manipulations were collected from the autogamous clone and grown to flowering in a greenhouse under long-day conditions $(16 \mathrm{~h}) . \mathrm{S}_{2}$ and $\mathrm{S}_{3}$ generation seeds were produced from $11 S_{1}$ and $16 S_{2}$ plants, respectively, that were selected at random from seeds of bulk populations of each and grown under similar greenhouse conditions with only unassisted selfing (no hand manipulations). AG-S4 is a composite of equal numbers of $S_{4}$ seeds produced from $12 S_{3}$ plants.

Leaves from AG-S4 are more ovate and lighter green than the original autogamous MU-81 clone which displays typical L. corniculatus morphology. AG-S4 exhibits no inbreeding vigor depression when compared to MU-81 and is a prolific 